\title{
Recoding, storage, rehearsal and grouping in verbal short-term memory: an fMRI study
}

\author{
R.N.A. Henson ${ }^{\mathrm{a}, \mathrm{b}, *}$, N. Burgess ${ }^{\text {b, c }}$, C.D. Frith ${ }^{\mathrm{a}}$ \\ ${ }^{\mathrm{a}}$ Wellcome Department of Cognitive Neurology, Institute of Neurology, 12 Queen Square, London WC1N 3BG, UK \\ ${ }^{\mathrm{b}}$ Institute of Cognitive Neuroscience, University College London, 10, Queen Square, London WC1N 3BG, UK \\ ${ }^{\mathrm{c}}$ Department of Anatomy, University College London, Gower Street, London WC1E 6BT, UK
}

Received 29 July 1998; accepted 6 July 1999

\begin{abstract}
Functional magnetic resonance imaging (fMRI) of healthy volunteers is used to localise the processes involved in verbal shortterm memory (VSTM) for sequences of visual stimuli. Specifically, the brain areas underlying (i) recoding, (ii) storage, (iii) rehearsal and (iv) temporal grouping are investigated. Successive subtraction of images obtained from five tasks revealed a network of left-lateralised areas, including posterior temporal regions, supramarginal gyri, Broca's area and dorsolateral premotor cortex. The results are discussed in relation to neuropsychological distinctions between recoding and rehearsal, previous neuroimaging studies of storage and rehearsal, and, in particular, a recent connectionist model of VSTM that makes explicit assumptions about the temporal organisation of rehearsal. The functional modules of this model are tentatively mapped onto the brain in light of the imaging results. Our findings are consistent with the representation of verbal item information in left posterior temporal areas and short-term storage of phonological information in left supramarginal gyrus. They also suggest that left dorsolateral premotor cortex is involved in the maintenance of temporal order, possibly as the location of a timing signal used in the rhythmic organisation of rehearsal, whereas Broca's area supports the articulatory processes required for phonological recoding of visual stimuli. (C) 2000 Elsevier Science Ltd. All rights reserved.
\end{abstract}

Keywords: Working memory; Connectionist model

\section{Introduction}

Verbal short-term memory (VSTM) has been the subject of considerable psychological, neuropsychological and developmental research, culminating in successful theories such as the Phonological Loop of Baddeley [2]. This research has recently been supplemented by both functional neuroimaging $[1,36,46]$ and computational modelling $[7,8,23,34]$. As such, theories of VSTM sit at the juncture of several strands of

\footnotetext{
Research performed at: The Wellcome Department of Cognitive Neurology, Institute of Neurology, 12 Queen Square, London WC1N 3BG, UK

* Corresponding author. Tel.: +44-171-833-7483; fax: +44-171813-1420.

E-mail address: r.henson@fil.ion.ucl.ac.uk (R.N.A. Henson).
}

evidence. The present study used fMRI to identify the neural correlates of the basic processes in VSTM and, at a more detailed level, the components of a connectionist model of the Phonological Loop [10].

The basic processes assumed to be involved in VSTM for visually-presented material are shown schematically in Fig. 1. These processes are: (a) recoding, during which visual material is transcoded into a phonological form; (b) storage, during which phonological material is held temporarily, subject to loss by decay or interference; (c) rehearsal, during which phonological material is refreshed via subvocal articulation; and (d) temporal grouping, whereby the rhythmic parsing of a sequence of items improves retention of their temporal order. We summarise the evidence for the dissociable nature of these processes, introducing both the 


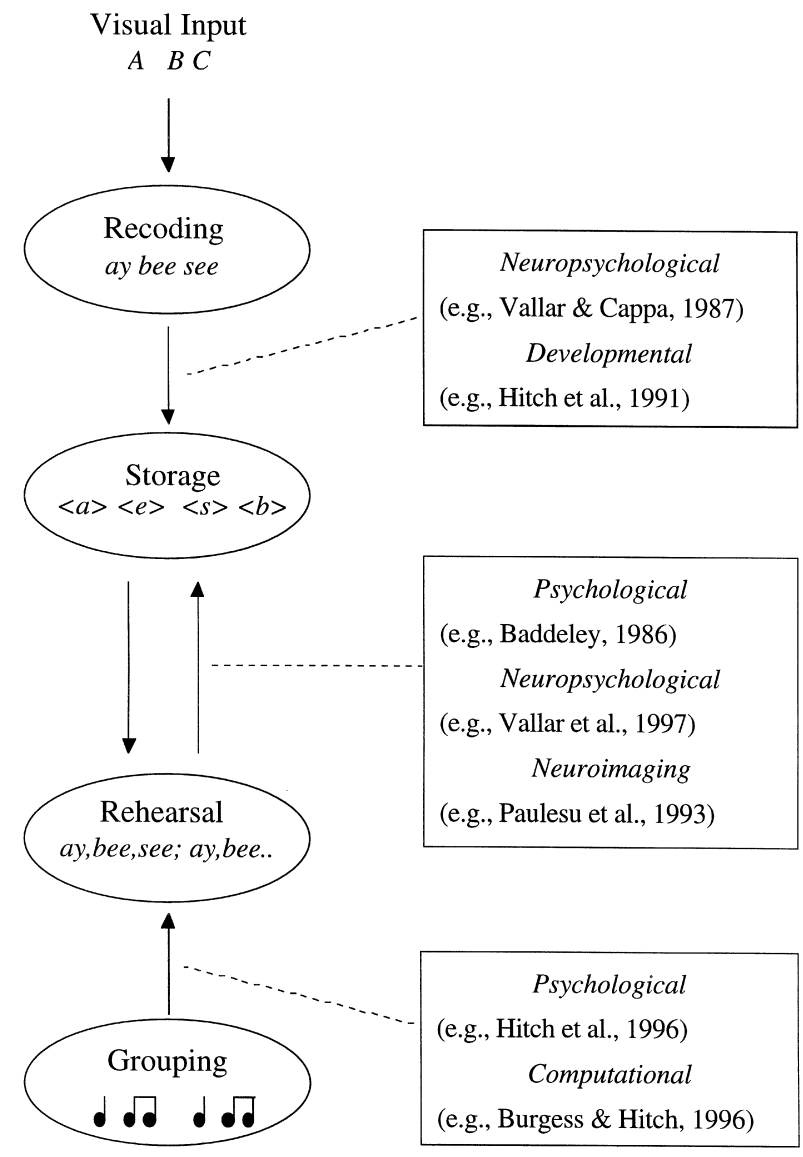

Fig. 1. Schematic depiction of processes assumed to be involved in short-term memory for visual-verbal material.

theoretical framework of the Phonological Loop and the connectionist model of Burgess and Hitch [10].

\subsection{Storage and rehearsal}

The Phonological Loop of Baddeley [2] comprises two components, a passive Phonological Store and an active Articulatory Control Process. Verbal material enters the Phonological Store and subsequently undergoes rapid decay unless rehearsed via the Articulatory Control Process. Two key empirical findings in support of this theory are the phonological similarity effect, whereby short-term memory is worse for similarsounding material, even when presented visually [16], and the word-length effect, whereby short-term memory is worse for words that take longer to articulate [4]. The former is attributed to confusions between similar representations in the Phonological Store; the latter is attributed to the extra time taken to rehearse longer words via the Articulatory Control Process. The role of articulatory processes is reinforced by the fact that suppression of articulation not only impairs performance by preventing rehearsal, but also removes the word-length effect [2].
Considerable numbers of patients have been reported with selective impairments of VSTM that are consistent with a damaged phonological store [54]. Some of these patients, such as JB [45] and PV [50], show severely impaired short-term memory for auditory-verbal material, combined with normal speech perception and production, normal long-term memory and normal short-term memory for nonverbal material. Another such patient, LA, who showed an impaired auditory memory span and no evidence of a phonological similarity effect nonetheless showed an effect of articulatory suppression on a serial pointing task, suggesting that she retained the ability to rehearse [53]. This pattern is consistent with a damaged Phonological Store, but intact Articulatory Control Process. By contrast, patient TO showed an intact phonological similarity effect with auditory presentation, but no evidence of rehearsal [53]. This pattern is consistent with an intact Phonological Store, but a damaged Articulatory Control Process. Patients LA and TO therefore provide a double dissociation of storage and rehearsal processes in VSTM.

Neuroanatomical localisation of phonological storage following brain damage has been reasonably consistent. Patients JB and LA for example, who are assumed to have an impaired phonological store, both have lesions to left temporo-parietal cortex (including the supramarginal and angular gyri in both cases $[53,56])$. Patients assumed to have impaired rehearsal possess a more varied pattern of damage (TO had lesions in premotor, rolandic, frontal paraventricular and anterior insula areas of the left hemisphere; patient GF [52] showed severe cerebellar atrophy, perhaps reflecting a ventral pontine infarction [12]; CM, cited in [18], suffered a bilateral ventral pontine lesion). More generally, Broca's area (left inferior premotor cortex, BA 44) is likely to play an important role in articulatory control processes, given its long association with speech output.

Neuroimaging studies have supported the neuropsychological evidence for the anatomical dissociation of storage and rehearsal in VSTM. For example, Paulesu et al. [36] used positron emission tomography (PET) to image brain activity during an item recognition task [47]. When images from the experimental task (that used English letters) were contrasted against those from the control task (that used unfamiliar symbols), activated areas included bilateral inferior prefrontal cortex (Broca's area, BA 44) and bilateral inferior parietal cortex (supramarginal gyri, BA 40). The authors proposed that these areas comprise part of Baddeley's Phonological Loop. To distinguish the storage and rehearsal components of VSTM, Paulesu et al. [36] compared a second task of rhyme judgement for the English letters with a control task of visual matching of the symbols. Subtraction in this case revealed sig- 
nificant activation in Broca's area, but not the left inferior parietal area. Given independent evidence that rhyme judgements require subvocal articulation [6,51], the authors argued that the inferior prefrontal area contributes to rehearsal in VSTM, therefore implicating the inferior parietal area as the locus of storage.

A similar PET study was reported by Awh et al. [1]. They compared both an item recognition task and a two-back task with controls requiring response to a single target item. Areas showing significant activation on the left in both subtractions included superior and posterior parietal (BA 7/40) and Broca's (BA 44) areas, broadly consistent with those found by Paulesu et al. [36]. To isolate the storage component, Awh et al. [1] subtracted from the two-back task a second control of continuous subvocal repetition of single items. This subtraction produced significant activation only in the parietal areas. Thus inferior parietal areas were again implicated in storage, whereas inferior frontal areas were implicated in rehearsal, consistent with the neuropsychological evidence and further supporting dissociable processes of storage and rehearsal (see $[31,46]$ for reviews).

\subsection{Recoding and rehearsal}

The existence of phonological similarity and word length effects with both visual and auditory presentation implies that visual inputs are recoded into a phonological form. As well as its role in rehearsal, the Articulatory Control Process has also been implicated in recoding visual material into the Phonological Store [2], because articulatory suppression removes the phonological similarity effect for visual material (but not auditory material, which is assumed to have direct access to the Phonological Store).

However, the dual role of Baddeley's Articulatory Control Process in recoding as well as rehearsal has been questioned by neuropsychological evidence. Vallar and Cappa [52] report two contrasting cases of anarthria following strokes. Patient MDC showed normal effects of phonological similarity and word-length with auditory material, but neither with visual material. Patient GF showed a normal effect of phonological similarity with both visual and auditory material, but no effect of word-length with auditory material. These results can be explained by assuming dissociable processes of recoding and rehearsal. MDCs deficit can be attributed to impaired recoding, but intact rehearsal, whereas GFs deficit can be attributed to normal recoding, but impaired rehearsal. This proposal has been bolstered by a patient CM studied by Nichelli and Cubelli (cited in [18]), who showed a clear effect of phonological similarity with both visual and auditory material, an effect of word-length with visual material, but no effect of word-length with auditory material. These deficits resemble those of GF, again explicable by intact recoding but impaired rehearsal, with the effect of word-length for visual material (which was not tested for GF) being attributed to the reasonable assumption that longer words take longer to recode. Data from these patients therefore comprise a double dissociation between recoding and rehearsal.

The neuropsychological evidence for a dissociation between recoding and rehearsal is also consistent with developmental studies of children's VSTM. Hitch et al. [27] reported that both 5- and 11-year olds show effects of phonological similarity and word-length when pictorial stimuli were named aloud, suggesting that rehearsal may begin as early as 5-year olds (though the authors also suggest alternative explanations). However, only the 11-year olds showed these effects when pictorial stimuli were viewed silently, suggesting that 5-year olds do not spontaneously recode visual material. According to conventional accounts of the phonological similarity and wordlength effects therefore, rehearsal and recoding dissociate developmentally, with rehearsal developing before recoding.

\subsection{Grouping and rehearsal}

Though Baddeley's Phonological Loop has been a valuable framework within which to view VSTM, it is not specified in sufficient detail to make precise predictions about performance on different memory tasks. Most notably, the theory does not specify how temporal order is represented in VSTM. The issue of temporal order is important because the majority of empirical dissociations underlying the theory, such as the effects of phonological similarity and word-length, are based on the memory span task, which requires recalling a novel sequence of items in the correct order. As a consequence, there has been much recent interest in computational models that make explicit assumptions about the representation of temporal order $[7,10,23,34]$.

One of the most successful of these is the neural network model of Burgess and Hitch [8-10]. Phonological storage corresponds to changes in short-term weights to and from item (lexical) nodes, and articulatory rehearsal corresponds to the recycling of activation around an input phonemes-item nodes-output phonemes loop, resulting in strengthening of the shortterm weights. The phonological similarity effect arises from confusions between similar representations on the input and output phoneme layers; the word-length effect arises from the decay of the short-term weights during the time taken to rehearse words. Auditory material activates the nodes in the input phoneme layer, whereas visual material activates the item nodes and/ or the output phoneme nodes via lexical and sublexical 
reading processes, respectively [15]. Articulatory suppression prevents recoding of visual material by occupying the layer of output phonemes: Because of its position within the input phonemes-item nodes-output phonemes loop, disruption of this layer prevents feedback to the input phoneme layer, removing the phonological similarity effect, and interferes with rehearsal, removing the word-length effect (see [10] for details).

An additional component of the Burgess and Hitch model that is absent from Baddeley's Phonological Loop is a timing signal. This timing signal is a dynamic signal that is used to represent temporal order in VSTM. For simplicity, it can be conceived as a wave of activity that moves across an array of nodes as each item is presented. The conjoint activity of the timing nodes and the item nodes allows each item to be associated with its position within a sequence (the presence of such positional information in VSTM being indicated by position-specific substitutions between sequences, errors that cannot be explained by alternative means of representing serial order such as item-item associations [23]). In reality, the timing signal may be derived from a set of temporal oscillators in the brain [7,24]. Rerunning the signal (resetting the oscillators) allows the item nodes to be reactivated in the appropriate order.

The timing signal is also assumed to underlie the temporal grouping effect: the dramatic improvement in memory span when sequences are grouped by the insertion of a pause every few (e.g. three) items [44]. Hitch et al. [26] showed that the temporal grouping effect is independent of word-length, phonological similarity and articulatory suppression, suggesting a distinct locus for the effect. They proposed that temporal structure in stimulus presentation recruits a second timing signal such that the original signal tracks the rhythm of items and the additional signal tracks the rhythm of the groups. The modulation of one signal by the other reduces the activation of items at incorrect positions, hence improving retention of serial order $[9,26]$. One purpose of the present study is to identify an anatomical locus for this timing signal by comparing rehearsal of grouped and ungrouped sequences.

\subsection{Present aims}

In the present study, we sought to extend our understanding of the functional anatomical specialisation of VSTM by designing five tasks that differed in their recoding, storage, rehearsal, and grouping requirements, successive subtractions of which were assumed to isolate each process. Firstly, we expected to replicate previous neuroimaging studies in finding separate brain areas associated with rehearsal and storage.
More importantly, we hoped our tasks would allow us to (1) separate areas used in recoding from those used in rehearsal, processes that have been confounded in previous studies, and (2) separate areas used in rehearsal from those used in temporal grouping, processes that have not been distinguished in previous analyses of VSTM. The ultimate aim was then to situate the components of the Burgess and Hitch model within the brain.

\section{Methods}

\subsection{Participants}

Informed consent was obtained from six, righthanded volunteers (four male; two female), aged between 22 and 30 (with a mean age of 27).

\subsection{Cognitive tasks}

Five tasks were designed in a hierarchical manner, such that the cognitive processes involved in one task were assumed to subsume those involved
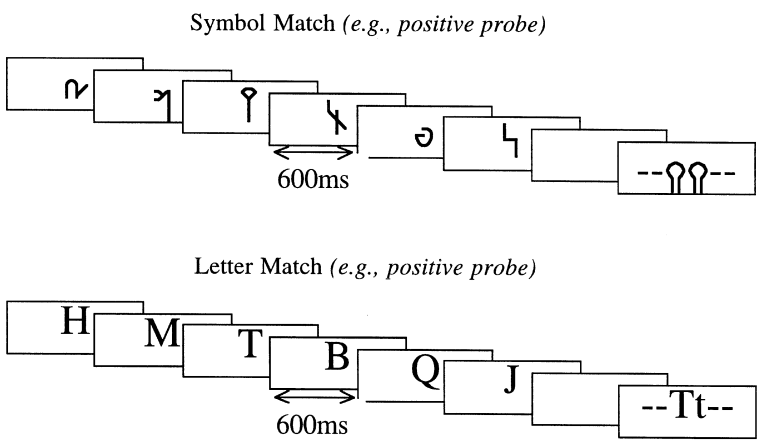

Letter Probe (e.g., positive probe)

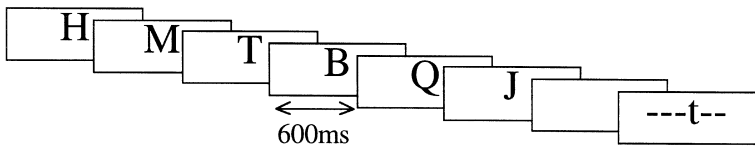

Sequence Probe (e.g., negative probe)

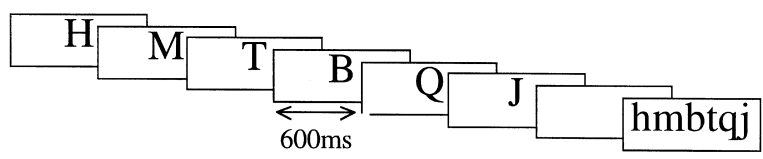

Grouped Probe (e.g., positive probe)

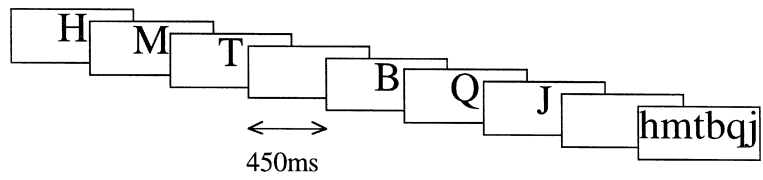

Fig. 2. Experimental procedure for a single trial of each task. 
in tasks lower in the hierarchy. The procedure associated with one trial of each task is shown in Fig. 2. All tasks involved sequential, visual presentation of six items, followed by a probe string prompting a yes-no manual response. The lowest level task was the Symbol Match task, in which the items were nonverbalisable symbols and the task was simply a same-different judgement for the two symbols in the probe string. This task was assumed to control for the visual input and motor output processes common to all five tasks (though the prior sequence of six symbols was irrelevant to performance of this particular task, participants were instructed to pay attention to them).

The next task in the hierarchy, the Letter Match task, was identical except that the symbols were replaced with letters, which participants were told to read silently to themselves. Subtraction of images obtained in the Symbol Match from those obtained in the Letter Match tasks was predicted to reveal the neural loci of phonological recoding of visualverbal material.

In the Letter Probe task, the probe consisted of a single letter and the judgement was for the presence or absence of that letter in the prior sequence of six letters. This was the first task to include an explicit memory component. Though Sternberg [47] proposed that performance of such a task requires serial scanning of item representations in memory, subsequent evidence has shown that the task is more likely associated with direct access to memory representations $[3,32,33]{ }^{1}$ More specifically, we assumed that this task involved access to a phonological store in addition to phonological recoding. The assumption that this task taxes phonological (rather than, say, visual) memory is supported by our previous findings of a phonological similarity effect using this task [25]. We predicted therefore that subtraction of images obtained in the Letter Match task from those obtained in the Letter Probe task would reveal the neural loci of storage in VSTM.

In the Sequence Probe task, the probe consisted of all six letters, presented simultaneously, and the judgement was for a match of their serial order (from left to right) with their temporal order in the prior sequence.

\footnotetext{
${ }^{1}$ Some previous imaging studies have employed variations of the Sternberg task and assumed that it does involve rehearsal $[1,36]$. These studies used slow presentation rates and a delay between presentation and recall; conditions under which participants are inclined to rehearse [33] (indeed, participants in the Paulesu et al. [36] study were explicitly instructed to rehearse). The rapid presentation and immediate probing in our Letter probe task are conditions under which previous psychological studies have denied a role for rehearsal [32,33], including our own analyses in previous uses of the Letter Probe task [25].
}

The probe string contained the same items as the prior sequence and, when the probe differed to the prior sequence, it differed only in the order of two adjacent items. On the basis of previous behavioural experiments [25], we were confident that this task, unlike the Letter Probe task, requires serial rehearsal. Whereas reaction times in the Letter Probe task are typically flat or even decrease across probe position, reaction times in the Sequence Probe task tend to grow monotonically with the position of the transposed items (at a rate of approximately $200 \mathrm{~ms}$ per position). This suggests that participants perform the Sequence Probe task by rehearsing the sequence from the first to the last item, until they find a mismatch with the probe string. These hypotheses were further supported by findings that the Sequence Probe task shows greater detrimental effects of concurrent articulatory suppression and irrelevant background speech than does the Letter Probe task. We therefore predicted that subtraction of images obtained from the Letter Probe task from those obtained in the Sequence Probe task would reveal the neural loci of subvocal, serial rehearsal.

Our final, highest-level task was the Grouped Probe task. This task was identical to the Sequence Probe task except that presentation of the sequence was grouped temporally into two groups of three by the insertion of a short pause after every third letter. As discussed in the Introduction, we predicted that grouping sequences during presentation would entail modification to the timing signal assumed to underlie serial rehearsal. Comparison of images obtained from the Sequence Probe with those obtained from the Grouped Probe task should reveal the neural loci of this timing signal.

\subsection{Experimental materials}

Letter sequences were generated by random selection without replacement from the set of 12 consonants BFHJLMPQRTYZ. The Symbol Match task used 12 nonverbalisable symbols taken from the false font of Howard et al. [30]. For the probe tasks, sequences were constructed such that (1) each Position 1-5 was probed equally often (Position 6 was never probed), and (2) there were equal numbers of positive and negative probes.

\subsection{Experimental procedure}

The items were presented in 32-point fonts on a Macintosh computer, projected onto a screen approximately $300 \mathrm{~mm}$ above the participant in the MRI scanner. The resulting visual angle for single items was approximately $2^{\circ}$. For the Symbol Match, Letter Match and Letter Probe tasks, the centred probe string was padded with hyphens to match the visual size of 
the probe string in the Sequence Probe and Grouped Probe tasks (see Fig. 2). The sequentially-presented letters were displayed in upper case and probe letters in lower-case, in order to minimise use of visual matching.

Items were presented every $600 \mathrm{~ms}(400 \mathrm{~ms}$ on, 200 ms off), except in the Grouped Probe task, in which they were presented every $450 \mathrm{~ms}(400 \mathrm{~ms}$ on, $50 \mathrm{~ms}$ off) and in which a $450 \mathrm{~ms}$ pause followed the third and the sixth item. This ensured that the total presentation time was equated in all conditions. The first item in each condition was preceded by a fixation cross (400 ms on; $200 \mathrm{~ms}$ off) and the sixth item was followed by extra $412 \mathrm{~ms}$ pause before the appearance of the probe. The probe remained in view for $4200 \mathrm{~ms}$, during which time participants used the index or middle finger of their right hand to make a 'yes' or 'no' response, respectively. The probe was followed by a $413 \mathrm{~ms}$ pause before the next trial began (giving a total trial length of $9225 \mathrm{~ms}$ ). The tasks were performed in blocks of four trials. Participants were given practice on the five tasks before entering the scanner, and a brief reminder of the instructions was displayed for $8.2 \mathrm{~s}$ at the start of each block.

\section{5. fMRI scanning technique}

A 2 T Siemens VISION system (Siemens, Erlangen, Germany) was used to acquire both $\mathrm{T} 1$ anatomical volume images $(1 \times 1 \times 1.5 \mathrm{~mm}$ voxels $)$ and volumes of $48 \mathrm{~T} 2 *$-weighted echoplanar slices $(64 \times 643 \times 3 \mathrm{~mm}$ pixels, $\mathrm{TE}=40 \mathrm{~ms}$ ) with blood oxygenation level dependent (BOLD) contrast. The $1.8 \mathrm{~mm}$-thick slices were acquired axially every $3 \mathrm{~mm}$, positioned to cover the whole brain. Data were recorded during two sessions, separated by a $2 \mathrm{~min}$ rest period. A total of 538 volume images were acquired continuously with an effective repetition time (TR) of $4.1 \mathrm{~s}$, with the first five volumes in each session being discarded to allow for $\mathrm{T} 1$ equilibration effects.

The blocks of four trials of each condition were presented in a box-car design, with the Symbol Match condition presented every other block. There were six repetitions of the other four conditions, the order of which was counterbalanced across the experiment. Each block lasted approximately $45.1 \mathrm{~s}$, during which time 11 volume images were acquired. The scanner was synchronised with the presentation of the first trial of each block, with the ratio of interscan to intertrial interval ensuring that voxels were sampled at different phases relative to trial onset.

\subsection{Data analysis}

Data were analysed using Statistical Parametric Mapping (SPM97 d, Wellcome Department of Cogni- tive Neurology, London, UK; [19]). All volumes were realigned to the first volume (actual head movement was $<2 \mathrm{~mm}$ in all cases) and the mean of the realigned volumes was coregistered with the structural T1 volume. The structural volume was then spatially normalised to a standard template (the canonical brain of [14]) in the space of Talairach and Tournoux [48] using non-linear basis functions. The derived spatial transformation was applied to the realigned $\mathrm{T} 2^{*}$ volumes, which were then spatially smoothed with a $10 \mathrm{~mm}$ FWHM isotropic Gaussian kernel (to accommodate further anatomical differences across subjects). The resulting timeseries across each session were highpass filtered with a cut-off of $180.4 \mathrm{~s}$, to remove lowfrequency drifts in the BOLD signal [28], and globally scaled to a Grand mean of 100. Mean images were then created by averaging across volumes acquired for each condition in each session.

The mean images were subjected to a general linear model comprising condition and subject effects at each voxel. Only voxels for which condition effects survived $P<0.001$ in an $F$-test were included in the analyses. Subsequent pairwise, planned contrasts across conditions produced statistical parametric maps of the $t$ statistic, which were subsequently transformed to the unit normal $Z$-distribution. The activations reported in Tables 1-4 consist of four or more contiguous voxels that survived an uncorrected threshold $P<0.001$ ( $Z$ $>3.09$ ) and the corresponding brain regions were identified by referring to structural images. We concentrate, in section 3 , on activations of those regions that have been implicated in verbal short-term memory by previous neuropsychological and neuroimaging studies.

\section{Results}

\subsection{Behavioural data}

As expected, performance was close to ceiling in all five conditions, with perfect performance in the Symbol Match and Letter Match tasks, and success rates of $0.88(\mathrm{SD}=0.04)$ for the Letter Probe task, 0.83 $(\mathrm{SD}=0.18)$ for the Sequence Probe task and 0.88 $(\mathrm{SD}=0.12)$ for the Grouped Probe task. None of the success rates differed significantly across probe tasks. The mean correct reaction times were $786 \mathrm{~ms}$ $(\mathrm{SD}=216), 993 \mathrm{~ms}(\mathrm{SD}=273), 1302 \mathrm{~ms} \quad(\mathrm{SD}=268)$, $2028 \mathrm{~ms}(\mathrm{SD}=521)$ and $2099 \mathrm{~ms}(\mathrm{SD}=2032)$, respectively. These reaction times increased significantly across the Symbol Match, Letter Match, Letter Probe and Symbol Probe tasks $(t(5)>3.22, P<0.05)$, but did not differ significantly between the Sequence Probe and Grouped Probe tasks. 
Table 1

Maxima within regions showing BOLD signal changes $(P<0.001$ uncorrected $)$ in comparison of symbol match and letter match tasks

\begin{tabular}{|c|c|c|c|c|c|c|c|}
\hline \multirow[t]{2}{*}{ Region of maximal activation } & \multirow[t]{2}{*}{ No. voxels } & \multirow[t]{2}{*}{ Left/right } & \multicolumn{3}{|c|}{ Talairach coordinates } & \multirow[t]{2}{*}{ Brodmann areas } & \multirow[t]{2}{*}{$Z$ value } \\
\hline & & & $x$ & $y$ & $z$ & & \\
\hline \multicolumn{8}{|l|}{ Increases in letter match } \\
\hline Middle frontal gyrus & 458 & $\mathrm{~L}$ & -51 & 6 & 42 & $6 / 9$ & 4.95 \\
\hline Inferior frontal gyrus & & $\mathrm{L}$ & -45 & 27 & 21 & 45 & 4.37 \\
\hline Inferior frontal gyrus & & $\mathrm{L}$ & -54 & 18 & 18 & 44 & 4.32 \\
\hline Middle frontal gyrus & 25 & $\mathrm{R}$ & 54 & 15 & 39 & 9 & 4.15 \\
\hline Anterior cingulate gyrus & 20 & $\mathrm{~B}$ & 6 & 27 & 39 & $8 / 32$ & 3.83 \\
\hline Middle temporal gyrus & 91 & $\mathrm{~L}$ & -66 & -36 & -3 & 21 & 4.15 \\
\hline Middle temporal gyrus & 23 & $\mathrm{R}$ & 69 & -48 & -3 & 21 & 4.21 \\
\hline Superior parietal gyrus & 135 & $\mathrm{~L}$ & -33 & -48 & 57 & 7 & 3.98 \\
\hline Inferior parietal gyrus & & $\mathrm{L}$ & -33 & -45 & 39 & 40 & 3.56 \\
\hline Superior parietal gyrus & 150 & $\mathrm{R}$ & 36 & -54 & 54 & 7 & 4.18 \\
\hline Inferior parietal gyrus & & $\mathrm{R}$ & 54 & -33 & 51 & 40 & 3.48 \\
\hline Precuneus & 21 & $\mathrm{~B}$ & 9 & -69 & 42 & 7 & 3.45 \\
\hline Fusiform gyrus & 109 & $\mathrm{~L}$ & -57 & -57 & -15 & $20 / 37$ & 4.36 \\
\hline Fusiform gyrus & 12 & $\mathrm{~L}$ & -15 & -84 & -18 & 18 & 3.88 \\
\hline \multicolumn{8}{|l|}{ Increases in symbol match } \\
\hline Medial frontal & 622 & $\mathrm{~B}$ & 0 & 54 & 3 & 10 & 5.52 \\
\hline Middle temporal gyrus & 28 & $\mathrm{~L}$ & -66 & 0 & -18 & 21 & 3.67 \\
\hline Superior temporal gyrus & 7 & $\mathrm{R}$ & 54 & -9 & 6 & $22 / 42$ & 3.44 \\
\hline Medial temporal gyrus & 24 & $\mathrm{~L}$ & -33 & 15 & -21 & 28 & 4.36 \\
\hline Parahippocampal gyrus & 91 & $\mathrm{~L}$ & -21 & -36 & -18 & 36 & 4.18 \\
\hline Parahippocampal gyrus & 486 & $\mathrm{R}$ & 33 & -27 & -21 & 36 & 4.79 \\
\hline Inferior temporal gyrus & & $\mathrm{R}$ & 57 & -3 & -24 & $20 / 21$ & 4.42 \\
\hline Inferior temporal gyrus & 33 & $\mathrm{R}$ & 45 & -57 & -6 & 37 & 4.08 \\
\hline Angular gyrus & 11 & $\mathrm{~L}$ & -45 & -72 & 24 & 39 & 3.48 \\
\hline Precentral gyrus & 13 & $\mathrm{R}$ & 51 & -15 & 33 & 6 & 3.38 \\
\hline Posterior cingulate & 94 & $\mathrm{R}$ & 12 & -54 & 18 & $23 / 30$ & 4.68 \\
\hline Posterior cingulate & 13 & $\mathrm{~B}$ & 3 & -39 & 39 & 31 & 3.43 \\
\hline
\end{tabular}

Table 2

Maxima within regions showing BOLD signal changes $(P<0.001$ uncorrected $)$ in comparison of letter probe and letter match tasks

\begin{tabular}{|c|c|c|c|c|c|c|c|}
\hline \multirow[t]{2}{*}{ Region of maximal activation } & \multirow[t]{2}{*}{ No. voxels } & \multirow[t]{2}{*}{ Left/right } & \multicolumn{3}{|c|}{ Talairach coordinates } & \multirow[t]{2}{*}{ Brodmann areas } & \multirow[t]{2}{*}{$Z$ value } \\
\hline & & & $x$ & $y$ & $z$ & & \\
\hline \multicolumn{8}{|l|}{ Increases in letter probe } \\
\hline Inferior frontal gyrus & 228 & $\mathrm{~L}$ & -42 & 24 & -9 & 47 & 4.82 \\
\hline Inferior frontal gyrus & 200 & $\mathrm{R}$ & 48 & 24 & -3 & 47 & 4.60 \\
\hline Middle frontal gyrus & 72 & $\mathrm{~L}$ & -33 & 54 & 3 & 10 & 3.92 \\
\hline Middle frontal gyrus & 45 & $\mathrm{R}$ & 33 & 51 & -6 & 10 & 3.79 \\
\hline Middle frontal gyrus & 8 & $\mathrm{R}$ & 39 & 39 & 21 & 46 & 3.46 \\
\hline Anterior cingulate & 265 & $\mathrm{~B}$ & 6 & 39 & 24 & $9 / 32$ & 4.80 \\
\hline Supramarginal gyrus & 65 & $\mathrm{~L}$ & -51 & -39 & 36 & 40 & 3.96 \\
\hline Supramarginal gyrus & 71 & $\mathrm{R}$ & 57 & -33 & 42 & 40 & 4.17 \\
\hline Caudate head & 19 & $\mathrm{R}$ & 15 & 9 & 9 & - & 3.58 \\
\hline Cerebellum & 6 & $\mathrm{R}$ & 21 & -66 & -45 & - & 3.45 \\
\hline Cerebellum & 6 & $\mathrm{R}$ & 39 & -39 & -39 & - & 3.44 \\
\hline Cerebellum & 5 & $\mathrm{~L}$ & -27 & -57 & -30 & - & 3.39 \\
\hline \multicolumn{8}{|l|}{ Increases in letter match } \\
\hline Middle occipital gyrus & 76 & $\mathrm{R}$ & 42 & -90 & 3 & $18 / 19$ & 4.71 \\
\hline Middle occipital gyrus & 5 & $\mathrm{~L}$ & -39 & -90 & 3 & 19 & 3.18 \\
\hline Precuneus & 23 & $\mathrm{R}$ & 18 & -84 & 42 & 19 & 3.59 \\
\hline Fusiform gyrus & 14 & $\mathrm{~L}$ & -18 & -87 & -18 & 18 & 3.57 \\
\hline Fusiform gyrus & 12 & $\mathrm{R}$ & 39 & -75 & -18 & 18 & 3.51 \\
\hline
\end{tabular}


Table 3

Maxima within regions showing BOLD signal changes $(P<0.001$ uncorrected $)$ in comparison of sequence probe and letter probe tasks

\begin{tabular}{|c|c|c|c|c|c|c|c|}
\hline \multirow[t]{2}{*}{ Region of maximal activation } & \multirow[t]{2}{*}{ No. voxels } & \multirow[t]{2}{*}{ Left/right } & \multicolumn{3}{|c|}{ Talairach coordinates } & \multirow[t]{2}{*}{ Brodmann areas } & \multirow[t]{2}{*}{$Z$ value } \\
\hline & & & $x$ & $y$ & $z$ & & \\
\hline \multicolumn{8}{|l|}{ Increases in sequence probe } \\
\hline Middle frontal gyrus & 17 & $\mathrm{~L}$ & -54 & 12 & 36 & 9 & 3.54 \\
\hline Superior parietal gyrus & 31 & $\mathrm{~L}$ & -24 & -51 & 51 & 7 & 4.07 \\
\hline Superior parietal gyrus & 77 & $\mathrm{R}$ & 27 & -54 & 51 & 7 & 5.05 \\
\hline Middle occipital gyrus & 586 & $\mathrm{~L}$ & -30 & -93 & 12 & 18 & 5.96 \\
\hline Fusiform gyrus & & $\mathrm{L}$ & -27 & -78 & -18 & 18 & 4.51 \\
\hline Middle occipital gyrus & 371 & $\mathrm{R}$ & 42 & -87 & 0 & 18 & 4.81 \\
\hline Fusiform gyrus & & $\mathrm{R}$ & 30 & -75 & -15 & 18 & 4.54 \\
\hline Cerebellum & 5 & $\mathrm{~B}$ & 3 & -60 & -21 & - & 3.26 \\
\hline \multicolumn{8}{|l|}{ Increases in letter probe } \\
\hline Inferior frontal gyrus & 17 & $\mathrm{R}$ & 51 & 36 & -18 & 47 & 3.88 \\
\hline Inferior frontal gyrus & 9 & $\mathrm{R}$ & 45 & 27 & 15 & 45 & 3.46 \\
\hline Anterior cingulate & 46 & $\mathrm{~L}$ & -3 & 42 & 24 & $9 / 32$ & 3.87 \\
\hline Superior temporal gyrus & 20 & $\mathrm{R}$ & 63 & -24 & 15 & $22 / 42$ & 3.96 \\
\hline Inferior temporal gyrus & 16 & $\mathrm{R}$ & 60 & -27 & -18 & $20 / 21$ & 3.65 \\
\hline Inferior parietal gyrus & 20 & $\mathrm{~L}$ & -33 & -66 & 45 & 40 & 3.67 \\
\hline Supramarginal gyrus & 51 & $\mathrm{~L}$ & -54 & -48 & 36 & 40 & 3.58 \\
\hline Cingulate gyrus & 38 & $\mathrm{~B}$ & -9 & -21 & 33 & 24 & 3.67 \\
\hline
\end{tabular}

\subsection{Imaging data}

\subsubsection{Comparison of letter match and symbol match tasks}

Subtraction of images in the Symbol Match task from those in the Letter Match task was predicted to reveal the neural regions involved in phonological recoding of visual-verbal material. As expected from previous imaging studies of reading [41,42], recoding was associated with a predominantly left-lateralised network of areas, including posterior frontal, inferior parietal, and posterior temporal regions (Table 1; Fig. $3 A)$. The frontal activation was maximal in lateral premotor cortex (BA 6) and extended inferiorly along the precentral sulcus into Broca's Area (BA 44) and anteriorly into inferior frontal sulcus (BA 9/45). The parietal activations were evident in both left and right superior and inferior parietal gyri (BA 7/40). The left temporal activations were evident in middle temporal
(BA 21) and inferior temporal/fusiform (BA 37) gyri. Less extensive right hemispheric activations were found in posterior middle frontal (BA 6/9) and middle temporal (BA 21) gyri. These right-sided activations may reflect distinct functions in recoding, or they may simply reflect 'spill-over' of activation via interhemispheric connections.

The opposite subtraction revealed extensive activations in medial frontal gyri (BA 10) and right anterior temporal gyri (BA 20/21). More focal activations were seen in bilateral parahippocampal gyri (BA 36), left anterior medial temporal gyrus (BA 28), and left angular gyrus (BA 39). The parahippocampal activations may reflect the relative novelty [49] of the false font symbols used in our task (previously unseen by our participants). Left anterior temporal and angular gyrus are often associated with lexical-semantic processing [43,55], and their relative deactivation in our Letter Match task may reflect an inhibition of

Table 4

Maxima within regions showing BOLD signal changes $(P<0.001$ uncorrected $)$ in comparison of grouped probe and sequence probe tasks

\begin{tabular}{|c|c|c|c|c|c|c|c|}
\hline \multirow[t]{2}{*}{ Region of maximal activation } & \multirow[t]{2}{*}{ No. voxels } & \multirow[t]{2}{*}{ Left/right } & \multicolumn{3}{|c|}{ Talairach coordinates } & \multirow[t]{2}{*}{ Brodmann areas } & \multirow[t]{2}{*}{$Z$ value } \\
\hline & & & $x$ & $y$ & $z$ & & \\
\hline \multicolumn{8}{|l|}{ Increases in grouped probe } \\
\hline Inferior frontal gyrus & 14 & $\mathrm{R}$ & 57 & 42 & -3 & 47 & 3.74 \\
\hline \multicolumn{8}{|l|}{ Increases in sequence probe } \\
\hline Middle frontal gyrus & 22 & $\mathrm{~L}$ & -42 & 9 & 54 & 6 & 3.94 \\
\hline Medial thalamus & 14 & $\mathrm{~L}$ & 0 & -3 & 9 & - & 3.55 \\
\hline
\end{tabular}




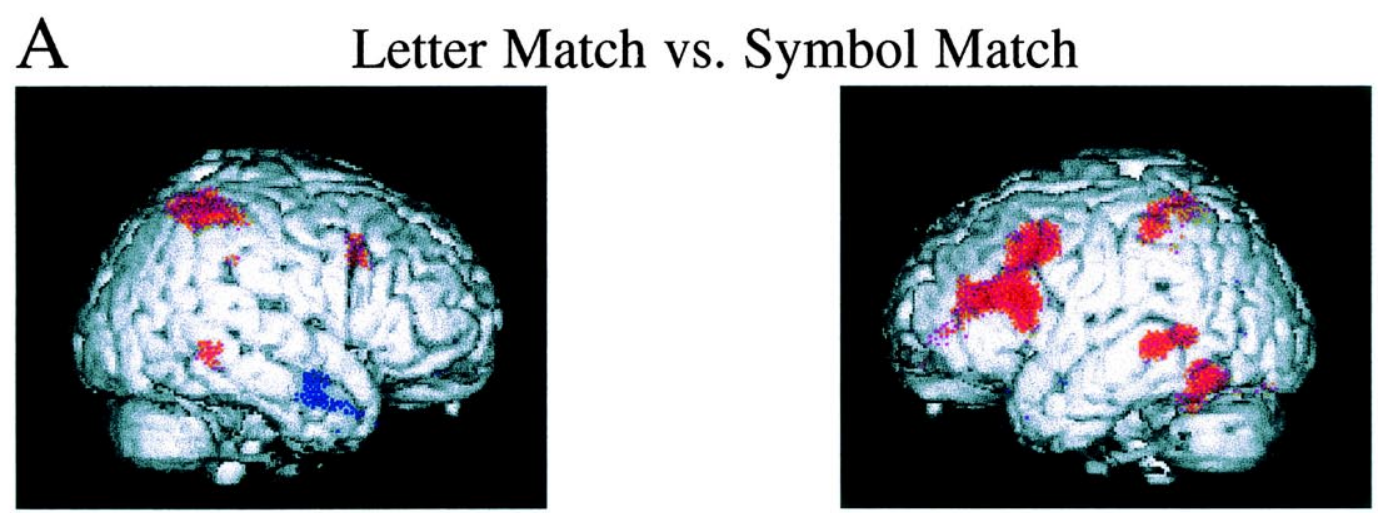

\section{B Letter Probe vs. Letter Match}
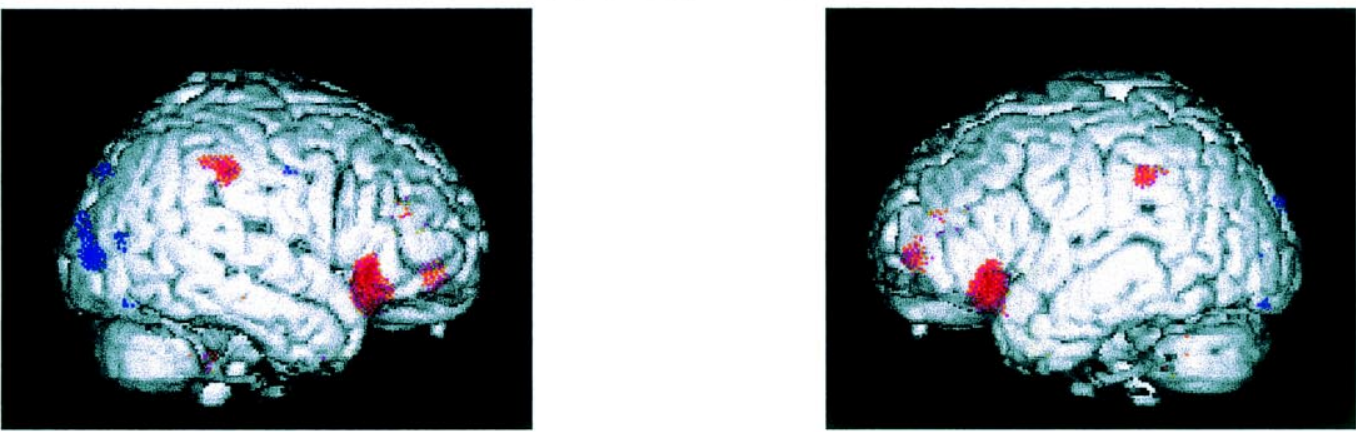

C

Sequence Probe vs. Letter Probe
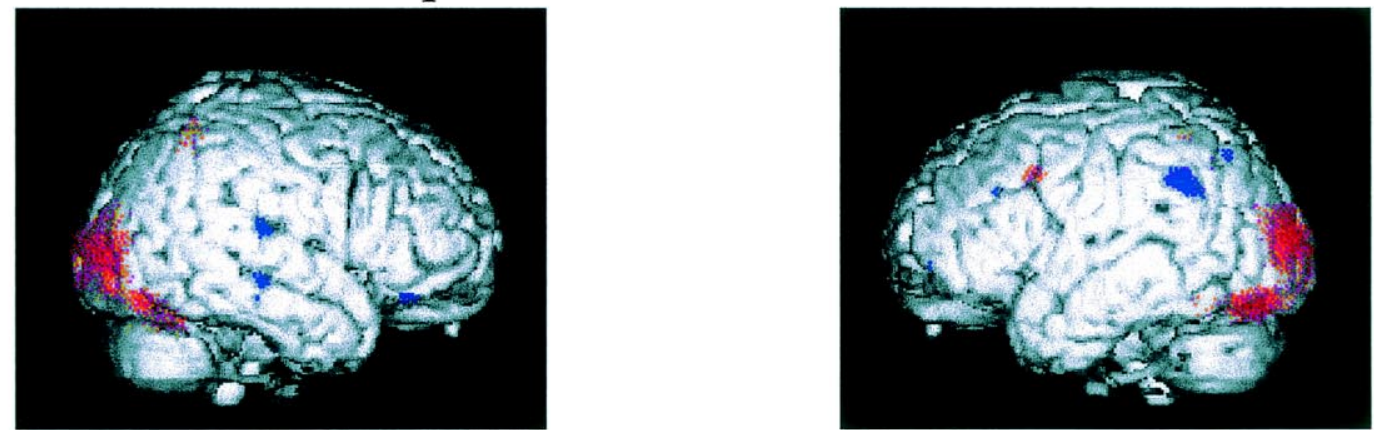

\section{$\mathrm{D}$}

\section{Grouped Probe vs. Sequence Probe}
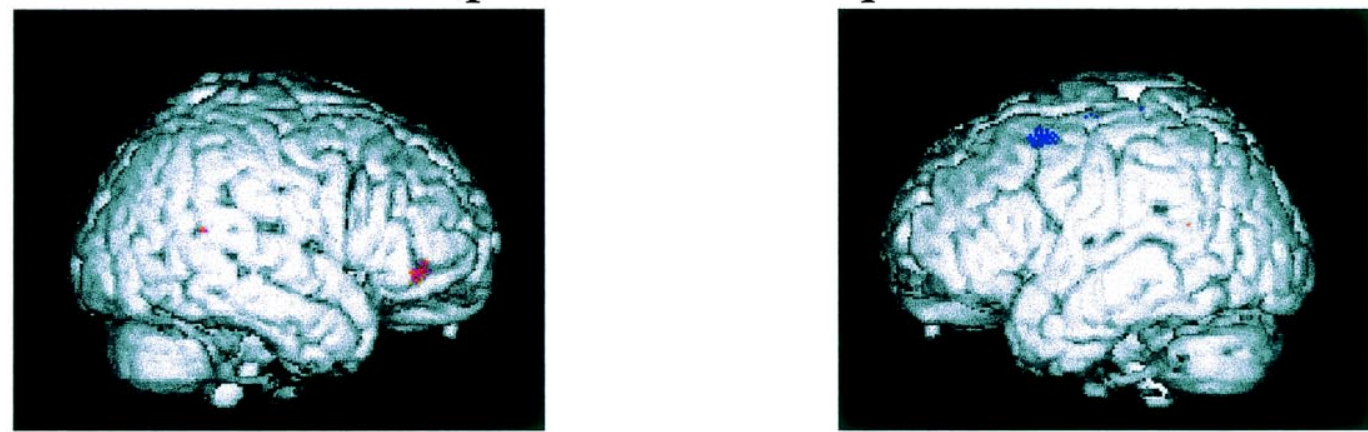

Fig. 3. Lateral areas on a rendered canonical brain that showed BOLD signal increases (red) and decreases (blue) in comparison of (A) the Letter Match task relative to Symbol Match task, (B) the Letter Probe task relative to the Letter Match task, (C) the Sequence Probe task relative to the Letter Probe task, and (D) the Grouped Probe task relative to Sequence Probe task. 
semantic retrieval, given that semantics are irrelevant to the task, as suggested by Price [41].

\subsubsection{Comparison of letter probe and letter match tasks}

Subtraction of images in the Letter Match task from those in the Letter Probe task was predicted to reveal the neural regions involved in phonological storage. Activations were observed in a bilateral frontal and parietal network (Table 2; Fig. 3B), comprising posterior inferior frontal (BA 47), anterior middle frontal (BA 10), anterior cingulate (BA 32) and supramarginal (BA 40) gyri. Right anterior frontal activation is often found during episodic retrieval [11], and left inferior frontal activation (inferior to Broca's area) is often associated with phonological retrieval $[37,43]$. Anterior cingulate activation has been associated with executive processes such as response selection [5,39] (e.g., deciding on criteria for successful recognition in our Letter Probe task). Most interesting is the activation of left supramarginal gyrus, slightly inferior to the inferior parietal activation identified in the Letter Match versus Letter Probe subtraction, and an area proposed by Paulesu et al. [36] as the locus of the phonological store. We cannot say whether our activation of the homologous right inferior parietal area also reflects phonological storage, or whether it is simply a consequence of hemispheric coactivation.

The opposite subtraction revealed only visual cortex activations, which may simply reflect greater visual processing for the two letter probe in the Letter Match task than the one letter probe in the Letter Probe task.

\subsubsection{Comparison of sequence probe and letter probe tasks}

Subtraction of images in the Letter Probe task from those in the Sequence Probe task was predicted to reveal the neural regions involved in subvocal, serial rehearsal (Table 3; Fig. 3C). Extensive bilateral activations were found in visual cortex, which probably reflect the greater visual complexity of the sequence probe (six letters) than the letter probe (one letter). The bilateral activations in superior parietal gyri (BA 7) and cerebellar vermis are most likely to reflect corresponding increases in visual attention and eye-movement associated with serial scanning of the sequence probe [17]. The most interesting activation was in left lateral premotor cortex (middle frontal gyrus, BA 6/9). Though this activation might also owe to differences in visual processing, it is not contained within the frontal eye fields identified by Paus [38]. Moreover, similar areas have been activated in previous imaging studies $[1,35]$, and in our Grouped Probe versus Sequence Probe comparison (see section 3.2.4), under conditions with no apparent difference in visual processing requirements. Rather, we attribute this activation to subvocal rehearsal: in particular, the temporal sequen- cing that is required in our Sequence Probe task but not our Letter Probe task.

The opposite subtraction revealed a number of focal activations which were not predicted. Most notable were two activations in left inferior parietal gyrus (BA 40 ), one of which is close to that found in the subtraction of Letter Match from Letter Probe images. Possible interpretations of this pattern of activity are considered in the Discussion.

\subsubsection{Comparison of grouped probe and sequence probe tasks}

Comparison of images in the Sequence Probe task with those in the Grouped Probe task was predicted to reveal the neural regions involved in temporal grouping. Only one region, in right inferior frontal gyrus (BA 47), was more active in the Grouped Probe than Sequence Probe task, and two regions, in left dorsolateral premotor cortex (BA 6) and medial thalamus, were more active in the Sequence Probe than Grouped Probe task (Table 4; Fig. 4D).

Differential right inferior frontal and medial thalamic activity was not predicted on the basis of previous studies. Left dorsolateral premotor cortex however has been associated with execution of sequential and rhythmic movements [13,21], and the present grouping-related deactivation was only slightly superior to the premotor activation found in the Sequence Probe minus Letter Probe subtraction. We attribute these premotor differences to a timing signal used in serial rehearsal and its modulation by temporal grouping.

\subsubsection{Activation profiles across all five conditions}

The activation profiles of four left-hemisphere regions identified by the above subtractions, in posterior middle temporal cortex, inferior parietal cortex (supramarginal gyrus), inferior frontal cortex (Broca's area), and lateral premotor cortex, are shown in Fig. 4. All four regions were activated in the letter tasks relative to the Symbol Match task. Activation in the middle temporal area (BA 21) differed little as a function of the type of letter task, whereas activation in the supramarginal area (BA 40) was greatest for the Letter Probe task. Broca's area (BA 44) showed greatest activation in the three memory tasks, but this activation differed little as a function of whether the tasks involved rehearsal or grouping. The premotor area (BA 6) on the other hand showed greatest activation in the Sequence Probe task, less in the Grouped Probe task, and least in the Letter Probe and Letter Match tasks. These activation profiles are discussed in relation to the computational model of Burgess and Hitch below. 

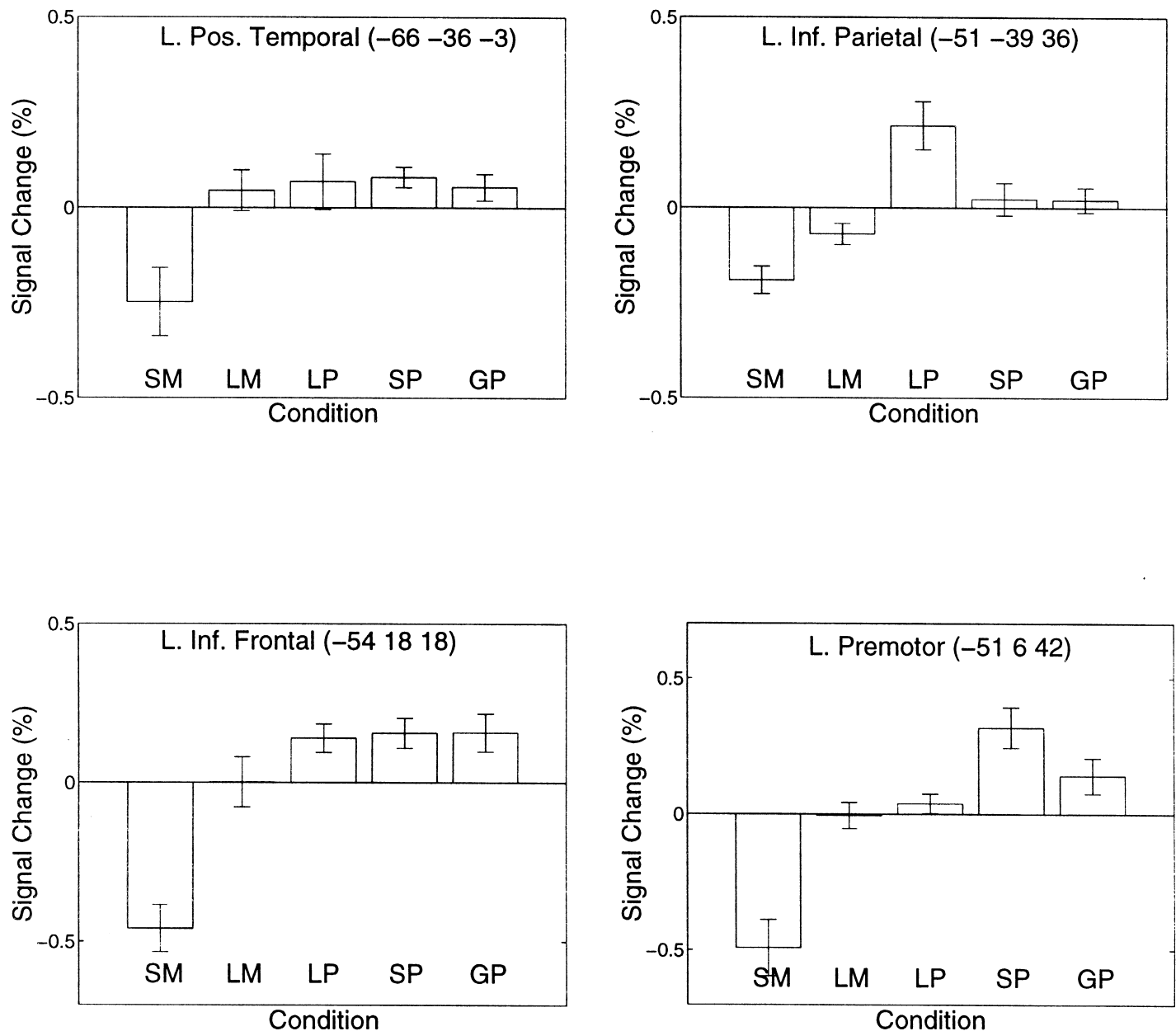

Fig. 4. Mean percentage signal change for each condition, relative to global across voxels and mean across conditions, within a 6 mm radius of the maxima identified in (A) left posterior middle temporal, (B) left inferior parietal (supramarginal gyrus), (C) left inferior frontal (Broca's area) and (D) left lateral premotor regions in Tables 2-4. Error bars show standard error of the mean across participants. SM=Symbol Match, $\mathrm{LM}=$ Letter Match, $\mathrm{LP}=$ Letter Probe, $\mathrm{SP}=$ Sequence Probe, $\mathrm{GP}=$ Grouped Probe.

\section{Discussion}

We examined VSTM using three tasks that required immediate memory for visually presented letters (Letter Probe, Sequence Probe and Grouped Probe tasks), a task that required matching visual letters (Letter Match task), and a task that required matching visual symbols (Symbol Match task). All tasks involving letters activated a network of mainly left-lateralised regions relative to the Symbol Match task. Some of these regions (e.g. posterior temporal regions) appeared to be concerned solely with phonological recoding (silent reading), being no more active in the mnemonic tasks than in the Letter Match task. Other regions, predominantly frontal and parietal, showed activity that was modulated by the particular demands of the mnemonic tasks. Given that neuroimaging alone cannot demonstrate which of these activations are necessary for task performance, we concentrate below, where possible, on those regions that have been implicated by previous neuropsychological studies. In particular, the activation of left supramarginal and inferior frontal gyri in our Letter Probe relative to Letter Match task we attribute to storage and retrieval of phonological information. The left lateral premotor cortex activation in our Sequence Probe task relative to Letter Probe task we attribute to subvocal rehearsal of serial order. The deactivation of left dorsolateral premotor cortex in our Grouped Probe relative to Sequence Probe task we attribute to the exploitation of temporal grouping in maintaining serial order. We first elaborate these findings with respect to previous studies, and then incorporate the findings within a neuroanatomical instantiation of the connectionist model of Burgess and Hitch [10]. 


\subsection{Recoding}

Contrasting the Letter Match against Symbol Match task revealed a large network of activation, predominantly on the left, including Broca's area, parietal and posterior temporal regions. Lesions to Broca's area have long been associated with speech output disorders, and the activation of this area, together with more superior regions of premotor cortex, is therefore consistent with an articulatory role in recoding visual material [2]. The inferior parietal activation is consistent with a role for this region in sublexical phonological processing of visual material [40], possibly including incidental storage of phonological information. The posterior temporal activations may reflect access to lexical representations of the letters [30].

\subsection{Storage}

Contrasting the Letter Probe against Letter Match task revealed activation in both frontal and parietal areas. As well as frontal areas consistent with those activated by phonological retrieval and episodic recognition in other studies, this contrast activated the left supramarginal gyrus. The interpretation of this location as the phonological store is consistent with previous functional imaging studies $[1,36]$ and with lesion sites in patients JB [56] and LA [53], who demonstrate specific impairments in storage. More generally, it is consistent with the temporoparietal damage seen in the majority of patients with VSTM deficits [54].

\subsection{Rehearsal}

Contrasting the Sequence Probe against Letter Probe task revealed activation in left lateral premotor cortex (BA 6). Activation in this premotor region is associated with rehearsal in previous imaging studies $[1,35,46]$, and was also modulated in our Grouped Probe versus Sequence Probe comparison. We interpret these activations as reflecting the rehearsal mechanisms used to maintain phonological traces of items in VSTM, particularly their temporal order. This rehearsal hypothesis is consistent with patient TOs premotor lesions and specific impairment in rehearsal but not storage [53].

The activation of a similar left premotor area in the comparison of Letter Match and Symbol Match task suggests that left premotor areas are involved in both rehearsal and recoding, consistent with the Phonological Loop [2]. There may be other areas that are critical for rehearsal but not recoding, as indicated by the impaired rehearsal but intact recoding shown by patients CM and GF [52] who have lesions in areas that were not activated in our comparison of Sequence Probe and Letter Probe tasks. As in all functional ima- ging studies, the lack of significant activation in particular regions cannot be interpreted. Another possibility is that patients $\mathrm{CM}$ and $\mathrm{GF}$ do in fact retain the ability to rehearse, but their rehearsal is not revealed by indices such as the word-length effect (see for example Della Salla et al. [18] for caveats concerning use of the word-length effect as an index of rehearsal).

We note that impaired recoding but intact rehearsal is also possible (as with patient MDC [52]), and may reflect the anatomical diversity of the areas associated with recoding. For example, lesions to the posterior temporal gyri, which were activated in our Letter Match versus Symbol Match comparison, but not our Sequence Probe versus Letter Probe comparison, may prevent recoding without preventing rehearsal (though MDCs temporal lesions were more anterior). This single dissociation of premotor involvement both in recoding and rehearsal, but posterior temporal involvement only in recoding, may also reflect two anatomically distinct recoding pathways, only one of which involves (sublexical) articulatory processes $[6,15]$.

Interestingly, Broca's area was not significantly activated in the Sequence Probe versus Letter Probe comparison. One possibility is that the dorsolateral premotor area is involved more in the serial processing of items, whereas Broca's area is involved more in the processing of their output phonology, with the latter being equally important for our Letter Probe and Sequence Probe tasks, given their common recoding requirement. Thus, though Broca's area may be important for articulatory processes involved in recoding visual material, it may not in fact be crucial for rehearsal or maintenance of serial order per se.

\subsection{Temporal grouping}

A nearby region in left dorsolateral premotor cortex was significantly less activated by our Grouped Probe than Sequence Probe task. Performance levels and mean correct reaction times for these two tasks did not differ detectably, and the tasks involved the same physical stimuli, differing only in the timing of presentation and the instructions given to participants.

Though the maximum of the premotor activation was slightly superior to that associated with the Sequence Probe versus Letter Probe comparison, the activations were coextensive at a lower threshold. This suggests that the activations correspond to the same functional region (i.e. a region involved in both temporal grouping and the maintenance of serial order). We interpret the effect of temporal grouping on dorsolateral premotor activity in terms of a modulation of the timing signal used to maintain serial order of items (see discussion of the Burgess and Hitch model in section 4.4.1). 


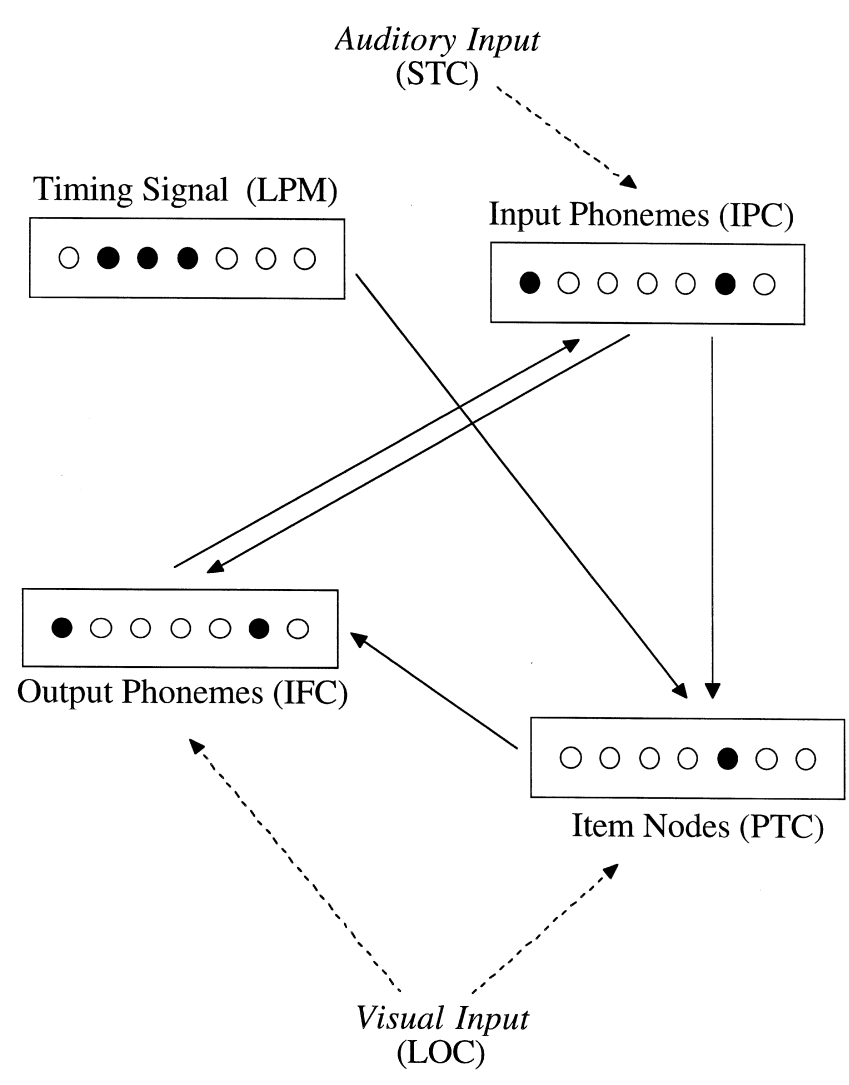

Fig. 5. One possible mapping of the Burgess and Hitch model onto the brain. Left hemisphere; LPM = lateral premotor cortex, IFC $=$ inferior frontal cortex (Broca's area), IPC $=$ inferior parietal cortex (supramarginal gyrus), $\mathrm{PTC}=$ posterior temporal cortex, $\mathrm{LOC}=$ lateral occipital cortex, STC = superior temporal cortex.

Activations in similar areas of premotor cortex have been reported in association with the execution of motor sequences. Catalan et al. [13] for example reported greater activation of a dorsal premotor region in sequential versus simple (repetitive) finger movements. Lesions of premotor cortex are also known to impair the reproduction of rhythmic motor sequences from memory [21]. Thus there is neuroimaging and neuropsychological precedence for a role of premotor cortex in temporal sequencing.

\footnotetext{
${ }^{2}$ We note that, like the timing signal, the "competitive queuing" process [29], by which one of multiple activated items is selected, is also required to a greater degree in our Sequence Probe and Grouped Probe tasks than in our Letter Probe task. Moreover, the degree of competition might be less for our Grouped than Sequence Probe tasks, given that a grouped timing signal reduces the activation of competing items in the model [10], consistent with the relative deactivation of dorsolateral premotor cortex in our Grouped Probe task. Thus a role for left dorsolateral premotor cortex in response competition and selection is an alternative possible explanation of our results.
}

\subsubsection{Anatomical instantiation of the Burgess and Hitch} model

On the basis of the above functional imaging results, we can propose a tentative mapping of the Burgess and Hitch model onto the brain (Fig. 5). For simplicity, where areas were activated bilaterally, we focus on the left hemisphere. The input phoneme layer would be situated in the inferior parietal (supramarginal) area identified by the Letter Probe task. The phonemic units in this layer are activated whenever phonological information is passed around the input phonemes-item nodes-output phonemes loop, resulting in the temporary strengthening of weights between these layers. Thus, we would expect the inferior parietal cortex to be active in any task involving phonological recoding or rehearsal. The input phoneme layer is also one of the layers assumed to subserve short-term item recognition tasks like our Letter Probe task, in which decisions are made on the basis of the strength with which item units are reactivated via the weights from the input phoneme layer [10]. The weights for items perceived recently will have had less time to decay, allowing them to be distinguished from items in previous trials (though less easily if those items share one or more phonemic units). Without input from the timing signal, discrimination between items on the basis of the phonemic input alone is likely to be more difficult, and could conceivably involve greater activity in this inferior parietal area.

The item layer, corresponding to lexical representations of words and letters, would be situated in the middle or inferior posterior temporal gyrus. Given that the item layer would be activated in all our tasks that used letters, these temporal regions would only be activated differentially in our Letter Match versus Symbol Match comparison. The output phoneme layer would be situated in Broca's area. The phonemic units of the output layer are assumed to be activated in both the recoding of visual items and in the rehearsal of phonological information around the input phonemes-item nodes-output phonemes loop. We would therefore also expect Broca's area to be activated in all our tasks that used letters.

The timing signal would be located in the dorsolateral premotor area identified in our Sequence Probe versus Letter Probe and Sequence Probe versus Grouped Probe comparisons. ${ }^{2}$ According to the model, the Sequence Probe task utilises the timing signal (for serial rehearsal), whereas the Letter Probe does not (relying only on recency judgements). The temporal structure in the Grouped Probe task recruits an additional timing signal that modulates the timing signal used to maintain the serial order of ungrouped stimuli, producing a more precise coding of temporal position. The finding that the same lateral premotor area is more active in the Letter Match task than Sym- 
bol Match task is not predicted by the Burgess and Hitch model, because the timing signal is only utilised in the temporal ordering of lexical items (mainly because the model has only been applied to short-term memory for lexical items). However, various extensions of the model to the ordering of sublexical items [20,22] assume additional timing signals to code, for example, the order of phonemes within a word. These extended models are consistent with a role for the timing signal in the recoding of polyphonemic visual material (e.g., the naming of letters).

\section{Conclusion}

In agreement with their previous functional dissociations, the processes of recoding, storage, rehearsal and grouping in verbal short-term memory appear to have dissociable anatomical bases. As predicted from previous neuropsychological and neuroimaging evidence, separate areas were implicated in storage and rehearsal, namely a left inferior parietal area in the former, and left prefrontal areas in the latter. As predicted from previous developmental and neuropsychological evidence, some areas, such as left posterior middle and inferior temporal gyri, were implicated in recoding visual-verbal material, but not in its rehearsal. Broca's area was also implicated in the phonological recoding of visual stimuli, but not serial rehearsal per se. By contrast, a left dorsolateral premotor area was clearly implicated in the serial rehearsal of temporal order. This premotor area was also differentially activated by temporal grouping of items. This is consistent with the presence of a timing signal, predicted by a computational model of VSTM [10] as necessary for the serial and rhythmic organisation of rehearsal. The present results allowed the functional components of this model to be mapped onto the brain. We feel that further investigation of the neural basis of VSTM will benefit from more detailed specification of "rehearsal", "storage" and "recoding", as necessitated by such explicit computational models. More generally, by attempting to situate computational models in functional neuroanatomy, we hope to provide a common framework in which psychological, neuropsychological and neuroimaging data can be evaluated both qualitatively and quantitatively.

\section{Acknowledgements}

RNAH and CF are supported by the Wellcome Trust. NB is supported by a Royal Society Research Fellowship. This work was supported by a BBSRC project grant to NB and Graham Hitch. We would like to thank Graham Hitch for many useful discus- sions, Oliver Josephs for helpful advice on fMRI experimental design, Tim Shallice and Cathy Price for reading a preliminary draft, and three anonymous referees for their comments during review.

\section{References}

[1] Awh E, Jonides J, Smith EE, Schumacher EH, Koeppe RA, Katz S. Dissociation of storage and rehearsal in verbal working memory. Psychological Science 1996;7:25-31.

[2] Baddeley AD. Working memory. Oxford: Oxford University Press, 1986.

[3] Baddeley AD, Ecob JR. Reaction times and short-term memory: implications of repetition effects for the high-speed exhaustive scan hypothesis. The Quarterly Journal of Experimental Psychology 1974;25:229-40.

[4] Baddeley AD, Thomson N, Buchanan M. Word length and the structure of short-term memory. Journal of Verbal Learning and Verbal Behavior 1975;14:575-89.

[5] Barch DM, Braver TS, Nystrom LE, Forman SD, Noll DC, Cohen JD. Dissociating working memory from task difficulty in human prefrontal cortex. Neuropsychologia 1997;35:1373-80.

[6] Besner D. Phonology, lexical access in reading and articulatory suppression: a critical review. The Quarterly Journal of Experimental Psychology 1987;39A:467-78.

[7] Brown GDA, Preece T, Hulme C. Oscillator-based memory for serial order. Psychological Review, 1999;106:551-81.

[8] Burgess N, Hitch G. Toward a neural network model of the articulatory loop. Journal of Memory and Language 1992;31:429-60.

[9] Burgess N, Hitch G. A connectionist model of STM for serial order. In: Gathercole S, editor. Models of short-term memory. London: Psychology Press, 1996. p. 51-71.

[10] Burgess N, Hitch GJ. Memory for serial order: a network model of the phonological loop and its timing. Psychological Review, 1999;106:551-581.

[11] Cabeza R, Nyberg L. Imaging cognition: an empirical review of PET studies with normal subjects. Journal of Cognitive Neuroscience 1997;9:1-26.

[12] Cappa SF, Pirovano C, Vignolo LA. Chronic 'locked-in' syndrome: psychological study of a case. European Neurology 1985;24:107-11.

[13] Catalan MJ, Honda M, Weeks RA, Cohen LG, Hallett M. The functional neuroanatomy of simple and complex sequential finger movements: a PET study. Brain 1998;121:253-64.

[14] Cocosco CA, Kollokian V, Kwan RKS, Evans AC. Brainweb: online interface to a 3D MRI simulated brain database. Neuroimage 1997;5:425.

[15] Coltheart M, Curtis B, Atkins P, Haller M. Models of reading aloud: dual-route and parallel-distributed-processing approaches. Psychological Review 1993;100:568-608.

[16] Conrad R, Hull AJ. Information, acoustic confusion and memory span. British Journal of Psychology 1964;55:429-32.

[17] Corbetta M, Miezin FM, Shulman GL, Petersen S. A PET study of visuospatial attention. The Journal of Neuroscience 1993;13(3):1202-26.

[18] Della Salla S, Logie RH, Marchetti C, Wynn V. Case studies in working memory: a case for single cases? Cortex 1991;27:16991.

[19] Friston KJ, Holmes AP, Worsley KJ, Poline JB, Frith CD, Frackowiak RSJ. Statistical parametric maps in functional imaging; a general linear approach. Human Brain Mapping 1995;2:189-210.

[20] Glasspool DW. Competitive queuing and the articulatory loop. 
In: Levy J, Bairaktaris $\mathrm{D}$, Bullinaria $\mathrm{J}$, Cairns $\mathrm{P}$, editors. Connectionist models of memory and language. London: UCL Press, 1996.

[21] Halsband U, Ito N, Tanji J, Freund HJ. The role of premotor cortex and the supplementary motor area in the temporal control of movement in man. Brain 1993;116:243-66.

[22] Hartley T, Houghton G. A linguistically constrained model of short-term memory for nonwords. Journal of Memory and Language 1996;35:1-31.

[23] Henson RNA. Short-term memory for serial order: the startend model. Cognitive Psychology 1998;36:73-137.

[24] Henson RNA, Burgess N. Representations of serial order. In: Bullinaria JA, Glasspool DW, Houghton G, editors. Proceedings of fourth neural computation and psychology workshop. London: Springer, 1997. p. 283-300.

[25] Henson RNA, Burgess N, Hartley T, Hitch GJ. Factors relevant to the Irrelevant Sound Effect, 1999 (in preparation).

[26] Hitch GH, Burgess N, Towse JN, Culpin V. Temporal grouping effects in immediate recall: a working memory analysis. The Quarterly Journal of Experimental Psychology 1996;49A:11639.

[27] Hitch GJ, Halliday MS, Schaafstal AM, Heffernan TM. Speech, "inner speech" and the development of short-term memory: effects of picture-labeling in recall. Journal of Child Psychology 1991;51:220-34

[28] Holmes AP, Josephs O, Büchel C, Friston KJ. Statistical modelling of low frequency confounds in fMRI. Neuroimage 1997;5:S480.

[29] Houghton G. The problem of serial order: a neural network model of sequence learning and recall. In: Dale R, Mellish C, Zock M, editors. Current research in natural language generation. London: Academic Press, 1990. p. 287-319.

[30] Howard D, Patterson K, Wise R, Brown WD, Friston KJ, Weiller G, Frackowiak RSJ. The cortical localisation of the lexicons. Brain 1992;115:1769-82.

[31] Jonides J, Reuter-Lorentz PA, Smith EE, Awh E, Barnes LL, Drain $\mathrm{M}$, et al. Verbal and spatial working memory in humans. In: Medin D, editor. The psychology of learning and motivation. London: Academic Press, 1996. p. 43-88.

[32] McElree B, Dosher BA. Serial position and set size in shortterm memory: the time course of recognition. Journal of Experimental Psychology: General 1989;118:346-73.

[33] Monsell S. Recency, immediate recognition memory and reaction time. Cognitive Psychology 1978;10:465-501.

[34] Page MPA, Norris DG. The primacy model: a new model of immediate serial recall. Psychological Review 1998;105:761-81.

[35] Paulesu E, Connelly CD, Frith CD, Friston KJ, Heather J, Meyers R, et al. Functional MR imaging correlations with positron emission tomography; initial experience using a cognitive activation paradigm on verbal working memory. Neuroimaging Clinics of North America 1995;5:207-25.

[36] Paulesu E, Frith CD, Frackowiak RSJ. The neural correlates of the verbal component of working memory. Nature $1993 ; 362: 342-4$.
[37] Paulesu E, Signorini M, Frith CD, Menoncello L, Cappa SF, Perani D, Fazio F. Functional heterogeneity of left inferior frontal cortex: explicit behavioural and PET evidence. Neuroimage 1997;5:S554.

[38] Paus T. Location and function of the human frontal eye-field: a selective review. Neuropsychologia 1996;6:475-83.

[39] Posner MI, Petersen SE. The attention system of the human brain. Annual Review of Neurosciences 1990;13:25-42.

[40] Price CJ. The functional anatomy of word comprehenson and production. Trends in Cognitive Sciences 1998;2:281-8.

[41] Price CJ. Functional anatomy of reading. In: Frackowiak RSJ, Friston KJ, Frith CD, Dolan RJ, Mazziotta JC, editors. Human brain function. Academic Press, 1998. p. 301-28.

[42] Price CJ, Friston KJ. The temporal dynamics of reading: a PET study. Proceeding of the Royal Society of London B 1997;264:1785-91.

[43] Price CJ, Moore CJ, Humphreys GW, Wise RJS. Segregating semantic from phonological processes during reading. Journal of Cognitive Neuroscience 1997;9:727-33.

[44] Ryan J. Grouping and short-term memory: different means and patterns of grouping. The Quarterly Journal of Experimental Psychology 1969;21:137-47.

[45] Shallice T, Butterworth B. Short-term memory impairment and spontaneous speech. Neuropsychologia 1977;15:729-35.

[46] Smith EE, Jonides J. Working memory: a view from neuroimaging. Cognitive Psychology 1997;33:5-42.

[47] Sternberg S. Memory scanning: mental processes revealed by reaction time experiments. American Scientist 1969;57:421-57.

[48] Talairach J, Tournoux P. Co-planar stereotaxic atlas of the human brain. Stuttgart: George Thieme Verlag, 1988.

[49] Tulving E, Markowitsch HJ, Craik FIM, Habib R, Houle S. Novelty and familiarity activations in PET studies of memory encoding and retrieval. Cerebral Cortex 1996;6:71-9.

[50] Vallar G, Baddeley AD. Fractionation of working memory: neuropsychological evidence for a phonological short-term store. Journal of Verbal Learning and Verbal Behaviour 1984;23:151-61.

[51] Vallar G, Baddeley AD. Phonological short-term store: phonological processing and sentence comprehension. Cognitive Neuropsychology 1984;1:121-41.

[52] Vallar G, Cappa SF. Articulation and verbal short-term memory: evidence from anarthria. Cognitive Neuropsychology 1987:4:55-78.

[53] Vallar G, DiBetta AM, Silveri MC. The phonological shortterm store-rehearsal system: patterns of impairment and neural correlates. Neuropsychologia 1997;35:795-812.

[54] Vallar G, Shallice T. Neuropsychological impairments of shortterm memory. Cambridge: Cambridge University Press, 1990.

[55] Vandenberghe R, Price C, Wise R, Josephs O, Frackowiak RSJ. Functional anatomy of a common semantic system for words and pictures. Nature 1996;383:254-6.

[56] Warrington EK, Logue V, Pratt RT. The anatomical localisation of selective impairment of auditory verbal short-term memory. Neuropsychologia 1971;9:377-87. 